\title{
FODDER CONSERVATION IN GRAZING SYSTEMS
}

\author{
K. J. HutCHINSON \\ CS̈IRO Pastoral Research Laboratory, Armidale, N.S.W.
}

Abstract

Grazing experiments at Armidale have shown variable responses in sheep production to fodder conservation.

(1) Responses to conseryation vary with stocking rate. At low stocking levels, responses are very small. At very high stocking levels, conservation practice may result in a lower production. The greatest response occurs at an intermediate stocking rate.

(2) Results depend on rainfall.

(3) Wool production may be increased by conservation but reproduction and growth are much less responsive in the Armidale environment.

These findings can be explained by a simple energy flow model. The model provides additional insights on factors such as the timing of feeding, the importance of hay quality and the relatively low potential of fodder conservation for increasing meat production.

\section{INTRODUCTION}

THIS PAPER deals with the effects of conserving hay in grazing systems where the fodder is produced and fed on the farm. Fodder may be conserved for two purposes, either to act as a long-term drought reserve or to reduce nutritional problems that occur within the year - e.g., in winter. Australian practice and experimentation have been concerned mainly with the latter purpose (Wheeler and Hutchinson, 1973).

Conservation has increased wool production and sheep survival in dry years only (Willoughby, 1958; Hamilton et al., 1972) and, in general, responses vary with stocking rate (Hutchinson, 1966; Bishop et al., 1968). In this paper some results from two long-term experiments are reported and the basis for responses is discussed in relation to a model of a fodder conservation/grazing system.

\section{EXPERIMENTS}

\section{BACKGROUND}

Armidale (lat. $30^{\circ} 31^{\prime} \mathrm{S}$, altitude $1070 \mathrm{~m}$ ) has a cool, temperate climate and a mean annual rainfall of approximately $750 \mathrm{~mm}$ 
with summer incidence of $65 \%$. The curves for mean rainfall and potential evapotranspiration are approximately parallel so that the distribution of the mean "effective" rainfall is not seasonal. However, rainfall variability is high both within and between years. Mean daily screen temperatures in January range from 24 " $\mathrm{C}(\max )$ to 12 " $\mathrm{C}(\mathrm{min})$; in July mean values of 11 " C $(\max )$ to $0 " \mathrm{C}(\mathrm{min})$ occur.

Conservation at a high level was compared with no conservation using a wide range of stocking rates. The experimental units were areas of well fertilized phalaris/white clover pasture stocked with Merino sheep. Conservation areas were enclosed for 10 weeks during the spring, and re-opened to grazing after the hay crops were removed. The hay was barn dried and the mean dry matter digestibility was about $60 \%$. . The hay crops from each treatment were fed to the sheep in the next autumn and winter and there was no carry-over of hay between years.

\section{'TRIAL 1}

Fine-woolled adult Merino wethers were set-stocked and grazed all year at rates of 10,20, and 30 sheep per hectare using four plots, each 0.4 ha, per stocking rate. Half of the number of plots were allocated to a fodder conservation treatment $(50 \%$ of 'area conserved in spring). The trial was run far 6 years,

\section{TRIAL 2}

This involved fine-woolled Merino ewes which lambed in spring. Replacement ewes were bred and grown on each of 12 plots (0.8 ha) using a 4-year replacement cycle. Wether lambs and surplus ewe lamb's were removed at 5 months of age. Setstocking and year-long grazing treatments were imposed at 3 rates $-10,14$, and 18 breeding ewes per hs. Fodder was conserved in half the number of plots ( $40 \%$, spring hay) and the remainder acted as controls. This experiment is still in progress but some of the findings over 5 years are presented here.

\section{RESULTS AND DISCUSSION}

\section{TRIAL 1}

Net wool production responses to haymaking are shown in Table 1. For the full year the gain at the low stocking rate was slight; the gain was larger at the intermediate stocking level and 
the response was substantially negative at the highest rate where the grazing intensity was extremely high. This interaction between fodder conservation and stocking rate is to be expected. At low stocking levels there is ample opportunity to conserve but there may be little need; where stock numbers are high there may be considerable need but little opportunity to lay down fodder reserves without incurring a loss of production. At some intermediate stocking level both the opportunity and the need may occur. Optimum combinations are likely between stocking rate and the amount of conservation as the percentage area conserved. These optima would vary from year to year but may be constrained by the general rule that only forage surplus to current requirements should be conserved.

TABLE 1: NET RESPONSES IN CLEAN WOOL PRODUCTION (kg/ha) TO HAYMAKING AT 3 STOCKING RATES - TRIAL I (Conserved minus Control: Mean of 6 years)

\begin{tabular}{|c|c|c|c|c|c|c|}
\hline Mean & No. of & & $\begin{array}{l}\text { Hay Crop } \\
\text { Enclosed } \\
\text { ys } 75\end{array}$ & $\begin{array}{l}\text { Interim } \\
\text { Period } \\
143\end{array}$ & $\begin{array}{l}\text { Hay } \\
\text { Fed } \\
144\end{array}$ & $\begin{array}{c}\text { Full } \\
\text { Year } \\
362\end{array}$ \\
\hline 10 sheep/ha & $\ldots$ & $\ldots$ & -0.36 & +0.43 & +0.61 & $+\quad 0.74$ \\
\hline 20 sheep/ha & $\ldots$ & $\ldots$ & -1.72 & +1.04 & +4.54 & $+\quad 3.86$ \\
\hline 30 sheep/ha & $\ldots$ & $\because \cdot \cdot$ & -4.01 & -6.60 & +0.26 & -10.35 \\
\hline
\end{tabular}

Annual responses can be divided into three phases:

(1) A period of about 10 weeks when the area to be conserved is enclosed and stacking intensity is increased on the grazing area that remains. At high stocking rates this can result in a substantial production "penalty" (Table 1).

(2) A period between hay making and feeding when the whole area of pasture is available for grazing. However, at high stocking rates there may be some carry-over effects due to cutting and heavy grazing (Table 1).

(3) A feeding period over which the major production benefits should occur (Table 1). There are, however, a number of physiological and behavioural factors that may act to modify the expected benefits. These will be discussed later by reference to the fodder model.

Data for individual years at the intermediate stocking level are shown in Table 2 . Responses, were variable and tended to be 
greater in years of lower rainfall. This suggests that some carryover of fodder from year to year would improve the effectiveness of the practice. For cool, temperate pastures where effective rainfall is not seasonally distributed, such as at Armidale, the best response occurs when a good spring is followed by a dry summer, autumn and winter. In southern areas of Australia, where the climate has a Mediterranean pattern, the responses may be related to the timing of the opening seasonal rains.

TABLE 2: YEARLY RAINFALL AND RESPONSE IN CLEAN WOOL PRODUCTION (kg/ha) TO HAYMAKING AT 20 SHEEP PER ha TRIAL 1

\begin{tabular}{|c|c|c|c|c|c|c|c|}
\hline Year & & & & $\begin{array}{r}\text { Rainfall } \\
\text { (mm) }\end{array}$ & Control & Conserved & Difference \\
\hline $1964-5$ & , I, & , , & ,... & 430 & 38.6 & 51.8 & +13.2 \\
\hline $1966-7$ & . & $\ldots$ & … & 907 & 67.2 & 62.0 & $=5.2$ \\
\hline 1967.8 & $\ldots$ & $\ldots$ & & 789 & 55.6 & 59.8 & +4.2 \\
\hline $1968-9$ & & & & 844 & 57.0 & 58.8 & $\begin{array}{r}+ \\
+\quad 1.8\end{array}$ \\
\hline $1969-70$ & & $\ldots$ & & 721 & 64.6 & 70.6 & +6.0 \\
\hline $1970-1$ & & $\ldots$ & & 1188 & 57.4 & 60.8 & $\begin{array}{l}1 \\
+\quad 3.4\end{array}$ \\
\hline
\end{tabular}

Tu^i 2

The effects of fodder conservation on lamb production are shown in Table 3. Responses. were negative or zero. The timing of the conservation and lambing operations may be responsible, in pert, for these surprising results. The autumn/winter feeding period is outside the periods of high nutritional demand and the withdrawal in spring of $40 \%$ of the grazing area may affect lactation and lamb growth, particularly at the intermediate and high stocking levels. If seasonal nutritional demand is timed to fit the peak of pasture growth in the spring, there may be little more to gain from a spring conservation' programme; it may even be counterproductive (Table 3). It is of interest to note the New

TABLE -3:- MEAN TOTAL WEIGHTS (kg/ha) of 5-MONTH MERINO LAMB PRODUCED OVER 5 YEARS IN EXCESS OF EWE LAMB REPLACEMENTS - TRIAL 2

(Spring hay $-40 \%$ area conserved)

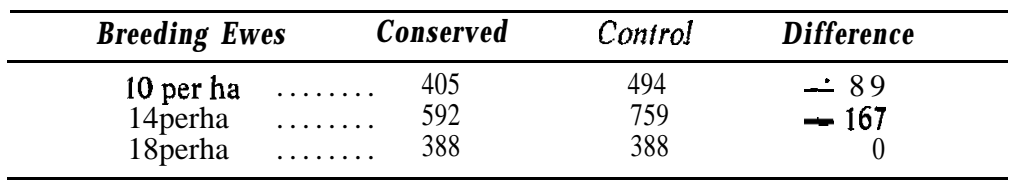


Zealand results of Campbell and Clayton (1966). These authors compared a "high" conservation programme with a "low" conservation programme using lactating cows calved in spring. The "low" conservation programme produced $12.5 \%$ more butterfat per lactation and the cows were $14 \mathrm{~kg}$ heavier at drying off. This response was 'attributed to a penalty effect from conserving too much spring hay in the high treatment (35\% of the area) .

In addition to the problem of penalty effects there is a further nutritional argument for explaining the failure of conservation to increase reproduction and body growth rates. This relates to voluntary intake constraints and digestibility and will be discussed in the section that follows.

\section{GRAZING/FODDER CONSERVATION MODEL}

Grazing systems are complex. Some of the underlying mechanisms and interactions can be studied by field experiments but it is becoming increasingly 'accepted that the approach of modelling can give some additional insights. and provide a more flexible approach for evaluating management practices. A simple productivity model for a fodder conservation/grazing system is illustrated in Fig. 1. Productivity can be evaluated in terms of energy flow (Macfadyen, 1963; Hutchinson, 1971). Plant chemical energy is utilized either by domestic animals or by other fauna and decomposers. The aim of management practices such as choice of stocking level and conservation is to increase the amount of energy utilized by domestic animals. Flows are represented by arrows (Fig. 1); the flows are rates and can be ex-

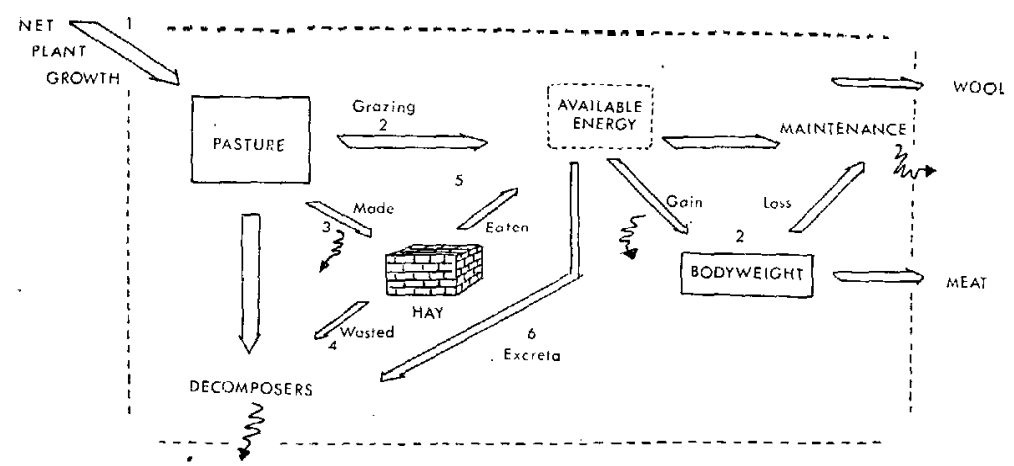

FIG. 1: The pathw ays of energy in a grazing/fodder conservation system. Heat production is indicated by the convoluted arrows. 
pressed as energy (megacalories or megajoules) per unit time. The model can be quantified and developed into a dynamic model for simulation studies by including controls on all the rates and by applying the relevant functional relationships that operate on the controls. However, such a development is not attempted in this paper; only the basic structure is given to provide a framework for discussing the successes and failures of fodder conservation'.

Plant shoot growth provides the input of energy. For a flock of grazing sheep this energy is processed into meat, wool and heat; heat is produced from the cost of maintenance, from the inefficiency of other processes - e.g., body gain - and from the respiration costs of a complex feed web of other fauna and cdecomposers. The basic aim of fodder conservation is to provide an additional energy flow loop - i.e., through "made-HAYeaten" (Fig. 1) in order to channel a higher amount of plant growth through the sheep flock. The six points at which success or failure of this operation depend are numbered (1-6) in Fig. 1. These are as follows:

(1) Combinations of stocking, cutting and feeding can affect botanical composition and pasture growth. Surplus herbage removed at low stocking rates may increase plant growth by improving light interception and photosynthetic efficiency. At high 'stocking levels a combination of grazing and cutting may depress pasture growth.

(2) Enclosing the hay crop may cause a reduction in grazing intake, wool production and the amount of body weight increase in spring. Body reserves may be important for wool production in dry sheep since the "gain-BODYWEIGHTloss" loop (Fig. 1) represents the animal's own conservation method.

(3) Variable losses are involved in hay making and storage. Most of the world's fodder research investigates this single point of a complex system.

(4) Feed refusals and wastage. occur. These can be related to the amount fed, the acceptability of the 'hay, and the level of pasture available in the feeding period.

(5) R-educed grazing activity accompanies the consumption of hay. This follows from gut fill constraints; sheep may reduce their pasture intake by as much as 0.8 units for every unit of hay eaten (author, unpublished). If pasture leaf 'area is 
low, this reduction may give a short-term increase in pasture growth. However, it should be noted that pasture "saved" is not static; shoot death and decomposition are continuous processes.

(6) It can be shown that the production response to conservation is sensitive to the difference in nutritive value between the hay and the pasture available at feeding. At Armidale, the digestibility of herbage consumed from improved pastures during the autumn and winter is comparable to good quality hay. In contrast, the autumn pasture residues in Southern Australia frequently have a dry matter digestibility of only $40 \%$.

Responses to conservation vary with different forms of animal production and this can be explained by the flows involved in the utilization of "\{available" energy. Only energy that is surplus to maintenance requirements is available for body gain. Because of the constraints of gut fill and low digestion rate, it is difficult for hay-fed animals: to ingest sufficient "available" energy to provide a surplus. Hence the major role for conservation in meat production is to reduce or prevent negative production - i.e., bodyweight loss to support the cost of maintenance. Wool production differs from meat production since maintenance corresponds to a survival level of feeding.

Despite the complexity of grazing systems, it is possible to accommodate the important mechanisms into a quantitative model. The structure alone of such models can give useful insights. The digital computer caa handle the complexity of the arithmetic for simulation runs which can give valuable experience in assessing the responses of the system to changing management practices. It is unlikely that these technique's will replace experiments based on real systems; their role will be a complementary one and their use will become increasingly commonplace.

\section{REFERENCES}

Bishop, A. H.; Birrell, H. A.; Tew, A,, 1968: J. Agric. Vic., 66: 112.

Campbell, A. G.; Clayton, D. G., 1966: Proc. Ruakura Fmrs' Conf.: 181. Hamilton, B. A.; Hutchinson, K. J.; Swain, G. F., 1972: Proc. Aust. Soc. Anim. Prod., 9: 214.

Hutchinson, K. J., 1966: J. Br. Grassld Soc., 21: 303.

1971: Herb. A bstr., 41: 1.

Macfadyen, A., 1963: In Animal Ecology. Pitman, London.

Wheeler, J. L.; Hutchinson, K. J., 1973: In The Pastoral Industry of Aus-

$\vdots$ tralla, Th. 7. Sydney Univ. Press.
Willoughby, W. M., 1958: Proc. A ust. Agrostology Conf., I: No. 54. 